\title{
Application of Response Surface Optimization Methodology in Designing Ordispersible Tablets of Antdiabetic Drug
}

\author{
Fatima Sanjeri Dasankoppa ${ }^{1 *}$, Hasanpasha N Sholapur ${ }^{2}$, Andanesh Byahatti ${ }^{3}$, Zaheer Abbas ${ }^{4}, \mathrm{Komal} \mathrm{S}^{5}, \mathrm{Kundu}$ Subrata ${ }^{6}$ \\ 'Department of Pharmaceutics, KLE College of Pharmacy, Vidyanagar, Hubballi, Karnataka, INDIA. \\ 2Department of Pharmacognosy, KLE College of Pharmacy, Vidyanagar, Hubballi, Karnataka, INDIA \\ ${ }^{3}$ Markson Pharma Ltd, Verna Industrial Estate, Verna, Goa-403722, INDIA. \\ ${ }^{4}$ Apotex Pvt.Ltd, Bangalore, Karnataka, INDIA. \\ ${ }^{5}$ Department of Pharmaceutics, Dr. MGR Educational and Research Institute, Chennai, Tamil Nadu, INDIA \\ Vergo Pvt. Ltd., Goa, INDIA.
}

\begin{abstract}
Objectives: The aim of the present investigation is to study the application of Response Surface Methodology (RSM), a mathematical model and graphical representation to formulate and Optimize Orodispersible Tablets (ODTs) of sitagliptin phosphate, a class III BCS drug. Methods: ODTs were prepared by direct compression method using dibasic calcium phosphate (DCP), as diluent and croscarmellose sodium sodium (CCS) as super disintegrant. Formulation was designed using design expert software 9.0 version. RSM based $2^{2}$ full factorial design, considering DCP and CCS as variables and dissolution time at 5,15 and 30 min was taken as response. Mathematical models in the form of regression equations and graphs were developed. Results: The adequacy of the developed mathematical models was statistically checked through the analysis of variance (ANOVA). The responses were analyzed using ANOVA and polynomial equation was generated for each response using RSM. Responses were mostly affected by the specific combinations of independent variable. $R^{2}$ predicted and $R^{2}$ adjusted values for the constructed models, which revealed the competence for the proposed mathematical model. Based on the results obtained DF1 formulation was optimized. The developed mathematical models can be
\end{abstract}

successfully used for their prediction of measured responses. Conclusion: DoE Concept in formulation could pave way for adaptation of Quality Based Design $(\mathrm{QbD})$ in pharmaceutical industry RSM was successfully applied to optimize diluents and disintegrate concentration of ODTs. The variables employed in the study had a great effect on the quality of formulation. Modeling of experimental data allowed the generation of useful equations for prediction of responses.

Key words: Response surface methodology, Optimization, Orally disintegrating tablets, Sitagliptin phosphate.

Correspondence

Dr. Fatima Sanjeri Dasankoppa,

Associate Professor, Department of Pharmaceutics, KLE College of Pharmacy, Vidyanagar, Hubballi, Karnataka, INDIA.

Phone: +919886678297

Email: fsdsankop@gmail.com

DOI: 10.5530/jyp.2020.12.35

\section{INTRODUCTION}

In this era of discovery of novel drug delivery systems, ODTs represent a rapidly emerging drug delivery system with industrial popularity and better patient compliance. These are most extensively used and widely acceptable dosage forms. ODTs are commonly known as orally disintegrating tablets, mouth dissolving tablets, fast dissolving tablets, or rapid melt tablets direct compression method is generally used for fast disintegrating tablets with the aid of super disintegrant as an important component. ${ }^{1,2}$ The fate of a drug in biological system is determined by the drug fraction that is bioavailable. Hence to deliver the drug and enhance its absorption rate, all the rapid melt tablets are developed using super disintegrants. ${ }^{3}$ This delivery system uses the combination of the feasibility of conventional solid dosage form tablets with that of the liquids and specifically desirable to pediatrics and geriatrics. ${ }^{4}$ MDTs can be taken without the aid of water as they rapidly disintegrate (in less than $1 \mathrm{~min}$ ) into the mouth and shows rapid absorption. Sitagliptin phosphate is an anti-diabetic drug and is classified under class III according to BCS (Biopharmaceutical Classification system) indicating high solubility and low permeability with high oral bioavailability, plasma half-life of $12.4 \mathrm{~h}$ and has an unpleasant taste. From past decade, there has been an increased demand for more patient-friendly and compliant dosage forms. As a result, the demand for developing new technologies has been increasing day by day. ${ }^{5,6}$ Thus, the present study aims to formulate ODTs by application of response methodology of sitagliptin phosphate and understand the variables employed in the study had a great effect on the quality of formulation. RSM is effective statistical method for relating the relationship between and dependent and independent parameters. RSM is particularly appropriate for product development work. The effectiveness of RSM in optimization of ingredient levels, formulations and processing conditions in pharmaceutical technology. RSM uses an experimental design such as central composite design to fit a model using least squares regression analysis. Adequacy of a proposed model is revealed by diagnostic checking provided by ANOVA and 3D response plots. RSM is also a useful tool to minimize the numbers of trials and provide multiple regression approach to achieve optimization. ${ }^{7}$ The risk involved in the development of oral disintegrating tablets is assessed by the Quality risk management which minimizes the risk involved during manufacture thereby providing continuous improvement in the development of product and process. This in turn results in high quality product with reduced process variables. ${ }^{8}$

\section{MATERIALS AND METHODS}

\section{Materials}

The materials used for the experiment include Sitagliptin phosphate, Calcium phosphate dibasic, Croscarmellose sodium, Magnesium stearate, Talc, Aspartame that were gifted from Vergo Pharma Research Laboratories Pvt. Ltd., Verna, Goa.

This is an open access article distributed under the terms of the Creative Commons Attribution-NonCommercial-ShareAlike 4.0 License, which allows others to remix, tweak, and build upon the work non-commercially, as long as the author is credited and the new creations are licensed under the identical terms. 


\section{METHODS}

\section{Compatibility study between drug and excipients}

The pure drug mixture of drug with excipients (1:1) were characterized by Fourier Transform Infrared (FTIR) Spectroscopy after exposure of physical mixture along with drug to $40 \pm 1^{\circ} \mathrm{C} / 75 \pm 5 \% \mathrm{RH}$ for 1 month to assess compatibility of drug with excipients. The scanning range was $500-$ $4000 \mathrm{~cm}^{-1}$ and the IR spectra of samples were obtained using $\mathrm{KBr}$ disk method..$^{910}$

\section{Formulation design by Design Expert}

$2^{2}$ Factorial -RSM based Design by varying two quantitative controllable factors (independent variables) DCP (X1) and CCS (X2) as shown in Table 1. API and recipients were mixed in geometrical ratio and passed through sieve \#30, magnesium separate and talc was passed through sieve \#60. The obtained blend was subjected for compression by using $8 \mathrm{~mm}$ punch Three dependent variables were selected as responses for representing the main parameters: Dissolution at $5 \mathrm{~min}$ (Y1), $15 \mathrm{~min}$ (Y2) and $30 \mathrm{~min}$ (Y3). After preliminary experiment, the upper and lower limits for the independent variables were established. DCP levels were from $20-60 \mathrm{mg} /$ tablet and CCS levels were 1-10mg /tablet. ${ }^{11-13}$

Four trials were performed for the evaluation of the optimized formulation (Table 2). The experimental data for each response variable were fitted to the quadratic Model. The regression parameters for the equations are calculated (Table 5 and 6).

\section{Preformulation studies}

Angle of repose, bulk density, tapped density and Carr's index was evaluated. ${ }^{14-17}$

\section{Post formulation studies}

Weight variation, tablet thickness, friability, wetting time or water absorption ratio were performed.

Table 1: $2^{2}$ level factorial design for orodispersible tablets.

\begin{tabular}{ccc}
\hline $\begin{array}{c}\text { Independent Variables } \\
\text { (Factors) }\end{array}$ & \multicolumn{2}{c}{ Levels } \\
\cline { 2 - 3 } & Low & High \\
\hline $\begin{array}{c}\text { Factor 1: } \\
\text { Calcium phosphate dibasic } \\
\text { Factors 2: }\end{array}$ & 20 & 60 \\
Croscarmellose sodium & 1 & 10 \\
\hline
\end{tabular}

With 2 factors at 2 levels, a full factorial design, consisting of 4 formulations was designed $\left(2^{2}=4\right)$

Table 2: Formulation design for orodispersible tablets.

\begin{tabular}{ccccc}
\hline $\begin{array}{c}\text { Ingredients } \\
(\mathrm{mg} / \mathrm{tab})\end{array}$ & \multicolumn{5}{c}{ Formulation code } \\
\cline { 2 - 5 } & DF1 & DF2 & DF3 & DF4 \\
\hline Sitagliptin Phosphate & 62.04 & 62.04 & 62.04 & 62.04 \\
Calcium phosphate dibasic & 60 & 20 & 60 & 20 \\
Croscarmellose sodium & 10 & 10 & 1 & 1 \\
Microcrystalline cellulose & 61.46 & 101.46 & 70.46 & 110.46 \\
Magnesium stearate & 2 & 2 & 2 & 2 \\
Talc & 2 & 2 & 2 & 2 \\
Aspartame & 2.5 & 2.5 & 2.5 & 2.5 \\
Total weight & 200 & 200 & 200 & 200 \\
\hline
\end{tabular}

Content uniformity was measured by studying the absorbance of aqueous solution at $265 \mathrm{~nm}$ using UV spectrophotometer. The concentration was calculated by using linear regression equation $\mathrm{y}=0.04 \mathrm{X}+0.002, \mathrm{R}^{2}=0.998$ with beers range of 5 to $45 \mu \mathrm{g} / \mathrm{ml}$ using $\mathrm{pH} 6.8$ phosphate buffer as reagent blank. ${ }^{16}$

\section{In vitro disintegration time}

Six tablets were placed in each tube of disintegration apparatus. The medium was maintained at $37 \pm 2^{\circ} \mathrm{C}$ and the time was noted for the entire tablet to disintegrate completely. ${ }^{16,17}$

\section{In vitro dissolution studies}

The in vitro drug releases were carried out in USP Type I (basket) dissolution apparatus to suit the physiological conditions of GIT. Aliquots of dissolution medium were withdrawn at predetermined time interval $5,10,15,20,30$ mins and the same volume of medium was replaced to maintain the constant volume. ${ }^{18,19}$

The adequacy of selection of variables was based on mathematical models and was statistically estimated through the ANOVA. The responses were analyzed using ANOVA and polynomial equation was generated. ${ }^{12}$ $R^{2}$ predicted and $R^{2}$ adjusted values for the constructed models, were obtained to check the competence for the proposed mathematical model. ${ }^{12,20}$ Based on the results obtained, formulation were optimized.

\section{RESULTS}

The linear regression analysis was done on absorbance data. Linear regression equation, Absorbance $=0.004 \mathrm{x}$ concentration +0.002 $(y=m x+c)$ was generated. Compatibility study between drug and excipients was by characterizing the physical mixture of drug and polymer by FTIR spectral analysis to assess any chemical alteration of the drug characteristics through its functional groups (Figure 1). Powder mixture containing drug with various excipients were subjected for preformulation studies including bulk density, tapped density, \% Carr's index, Hausner's ratio and angle of repose (Table 3). Four formulations

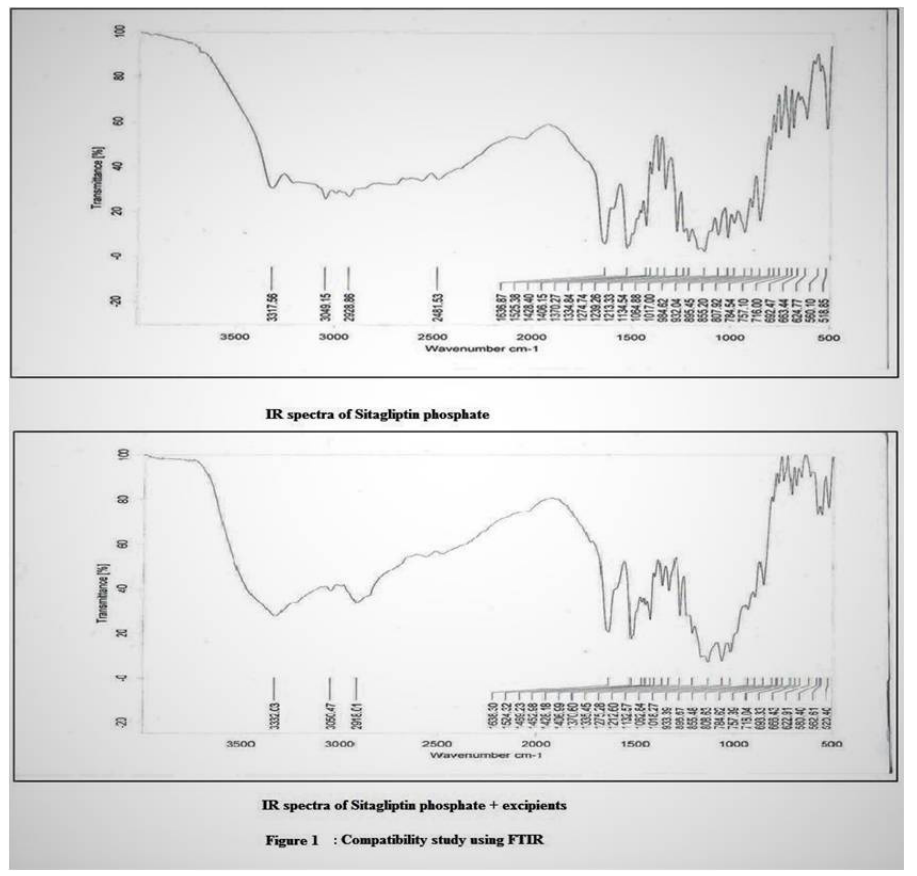

Figure 1: Compatibility studies using FTIR. 
Table 3: Data of Precompression parameters for formulations DF1-DF4.

\begin{tabular}{cccccc} 
Formulations & $\begin{array}{c}\text { Angle of repose } \\
(\theta)\end{array}$ & $\begin{array}{c}\text { Bulk density } \\
\left(\mathrm{gm} / \mathrm{cm}^{3}\right)\end{array}$ & $\begin{array}{c}\text { Tapped density } \\
\left(\mathbf{g m} / \mathrm{cm}^{3}\right)\end{array}$ & $\begin{array}{c}\text { Carr's index } \\
(\%)\end{array}$ \\
\hline DF1 & $25.20 \pm 0.015$ & $0.624 \pm 0.0005$ & $0.714 \pm 0.0005$ & $12.59 \pm 0.130$ \\
DF2 & $26.31 \pm 0.157$ & $0.655 \pm 0.0015$ & $0.755 \pm 0.0015$ & $13.23 \pm 0.026$ \\
DF3 & $26.51 \pm 0.186$ & $0.608 \pm 0.0005$ & $0.734 \pm 0.001$ & $17.07 \pm 0.062$ & $1.153 \pm 0.001$ \\
DF4 & $23.74 \pm 0.140$ & $0.624 \pm 0.0005$ & $0.734 \pm 0.0005$ & $14.93 \pm 0.07$ & $1.205 \pm 0.016$ \\
\hline
\end{tabular}

Table 4: Data Post compression parameters of formulations DF1-DF4.

\begin{tabular}{ccccccc} 
Formulations & $\begin{array}{c}\text { Weight variation } \\
(\mathbf{m g})\end{array}$ & $\begin{array}{c}\text { Thickness } \\
(\mathrm{mm})\end{array}$ & $\begin{array}{c}\text { Hardness } \\
(\mathrm{N})\end{array}$ & $\begin{array}{c}\text { Friability } \\
(\%)\end{array}$ & $\begin{array}{c}\text { Water absorption } \\
\text { ratio }\end{array}$ & $\begin{array}{c}\text { Drug content } \\
(\%)\end{array}$ \\
\hline DF1 & $200.85 \pm 1.136$ & $3.13 \pm 0.02$ & $53.66 \pm 2.516$ & $0.157 \pm 0.0144$ & $94.66 \pm 1.246$ \\
DF2 & $200.9 \pm 1.209$ & $2.91 \pm 0.01$ & $54 \pm 1.000$ & $0.182 \pm 0.0144$ & $95.83 \pm 2.229$ \\
DF3 & $200.85 \pm 1.182$ & $2.91 \pm 0.005$ & $55 \pm 1.000$ & $0.172 \pm 0.0015$ & $95.68 \pm 1.146$ & $99.33 \pm 1.527$ \\
DF4 & $200.05 \pm 1.234$ & $2.99 \pm 0.011$ & $54.33 \pm 0.577$ & $0.182 \pm 0.02886$ & $96.17 \pm 2.557$ & $97.33 \pm 1.527$ \\
\hline
\end{tabular}

Values are expressed as mean \pm SEM (Standard Error Mean);

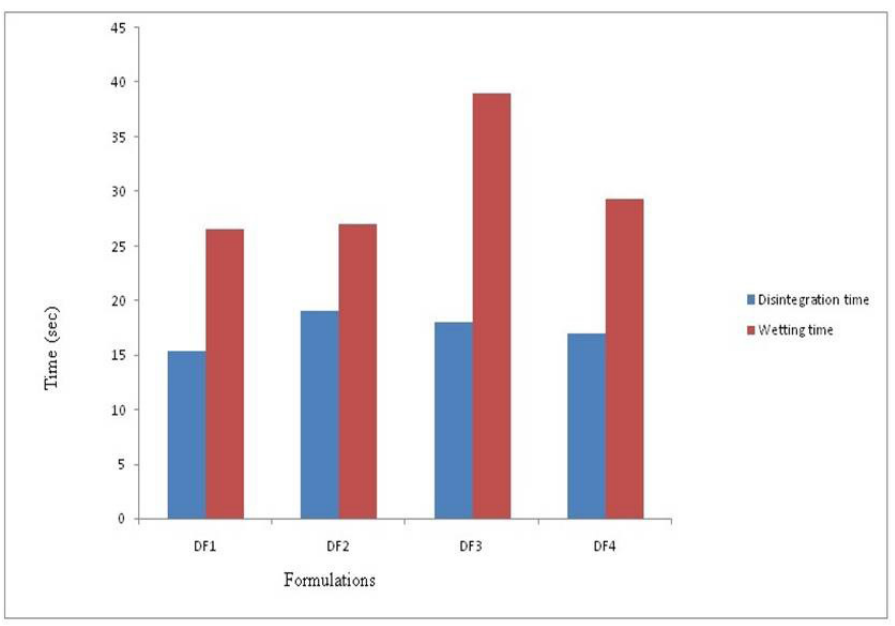

Figure 2: Comparison of disintegration time vs wetting time of formulations DF1-DF4.

Table 5: Summary of results of regression analysis for Responses Y1, Y2 and Y3.

\begin{tabular}{ccccccc}
\hline Response & $\boldsymbol{R}^{2}$ & $\begin{array}{c}\text { Adjusted } \\
\boldsymbol{R}^{2}\end{array}$ & $\begin{array}{c}\text { Predicted } \\
\boldsymbol{R}^{2}\end{array}$ & SD & $\% \mathrm{CV}$ & $\mathbf{P}$ \\
\hline Y1 & 0.9997 & 0.9990 & 0.9948 & 0.29 & 0.36 & 0.0180 \\
Y2 & 0.9992 & 0.9977 & 0.9876 & 0.52 & 0.61 & 0.0278 \\
Y3 & 0.9949 & 0.9847 & 0.9183 & 0.85 & 0.93 & 0.0715 \\
\hline
\end{tabular}

SD: Standard Deviation, \%CV: Coefficient of variation

were prepared by applying design expert software version 9.0 (Table 1, Table 2). The tablets were prepared by direct compression method.

The formulations were subjected for post formulation evaluations including thickness, hardness, friability, weight variation, in vitro disintegration time, wetting time, water absorption ratio, drug content, in vitro dissolution studies (Table 3 and 4, Figure 2 and 3) Based on the responses the data obtained was subjected to statistical analysis. 3D surface plots and polynomial equations were used to analyze effect of independent variables on dependent variables (Table 5-6, Figure 4-6).

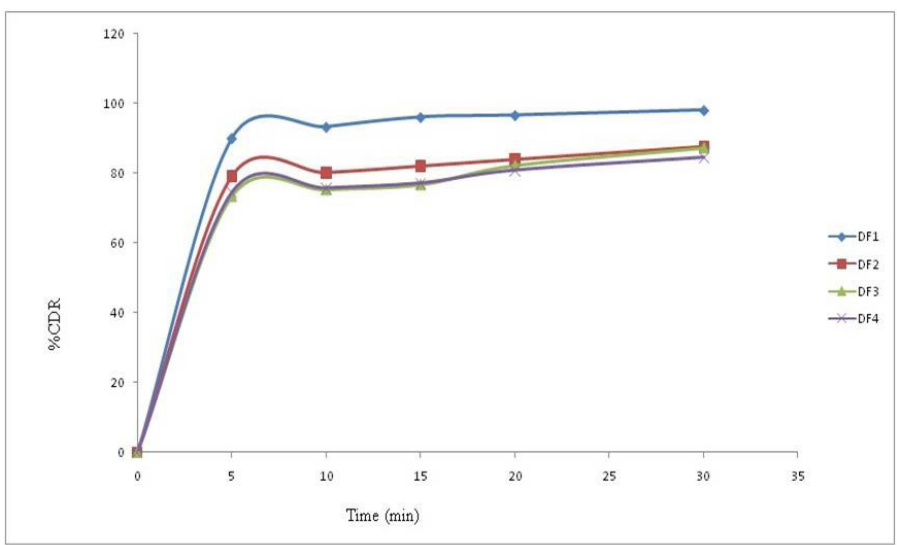

Figure 3: In vitro percentage drug release vs time of formulations DF1-DF4.

Table 6: Results of analysis of variance (ANOVA) for measured responses.

\begin{tabular}{|c|c|c|c|c|c|}
\hline Parameters & DF & SS & MS & $\mathrm{F}$ & Significance \\
\hline \multicolumn{6}{|c|}{$\% \mathrm{CDR}$ at $5 \mathrm{~min}$} \\
\hline Model & 2 & 267.84 & 133.92 & 1538.87 & \multirow{3}{*}{$\begin{array}{c}0.0180 \\
\text { Significant }\end{array}$} \\
\hline Residual & 1 & 0.087 & 0.087 & - & \\
\hline Total & 3 & 267.93 & - & - & \\
\hline \multicolumn{6}{|c|}{$\% \mathrm{CDR}$ at $15 \mathrm{~min}$} \\
\hline Model & 2 & 355.32 & 177.76 & 644.93 & \multirow{3}{*}{$\begin{array}{c}0.0278 \\
\text { Significant }\end{array}$} \\
\hline Residual & 1 & 0.28 & 0.28 & - & \\
\hline Total & 3 & 355.79 & - & - & \\
\hline \multicolumn{6}{|c|}{$\% \mathrm{CDR}$ at $30 \mathrm{~min}$} \\
\hline Model & 2 & 140.78 & 70.39 & 97.43 & 0.0715 \\
\hline Residual & 1 & 0.72 & 0.72 & - & \multirow{2}{*}{$\begin{array}{c}\text { Not } \\
\text { Significant }\end{array}$} \\
\hline Total & 3 & 141.50 & - & - & \\
\hline
\end{tabular}

DF: Degrees of Freedom, SS: Sum of Square, MS: Mean Sum of Square, F: Fischer's ratio

CDR-Cumulative drug release

Note: $P$ values less than 0.05 indicates model is significant 


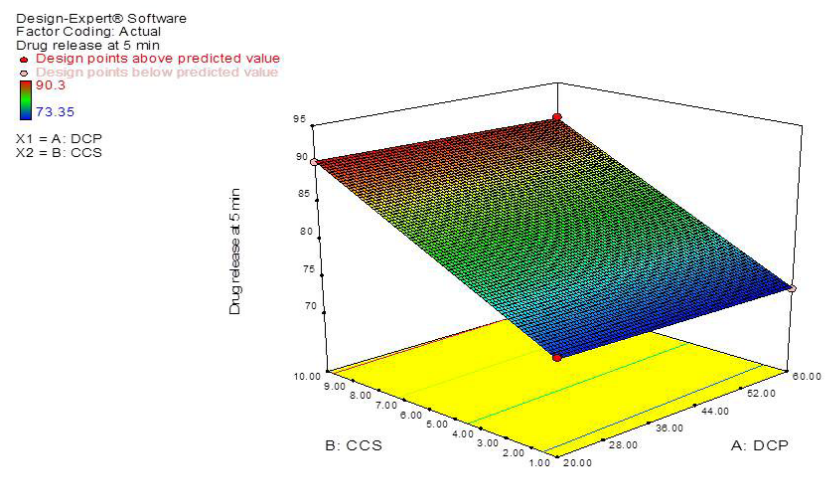

Figure 4: 3D response surface plots for in vitro drug release at $5 \mathrm{~min}$.

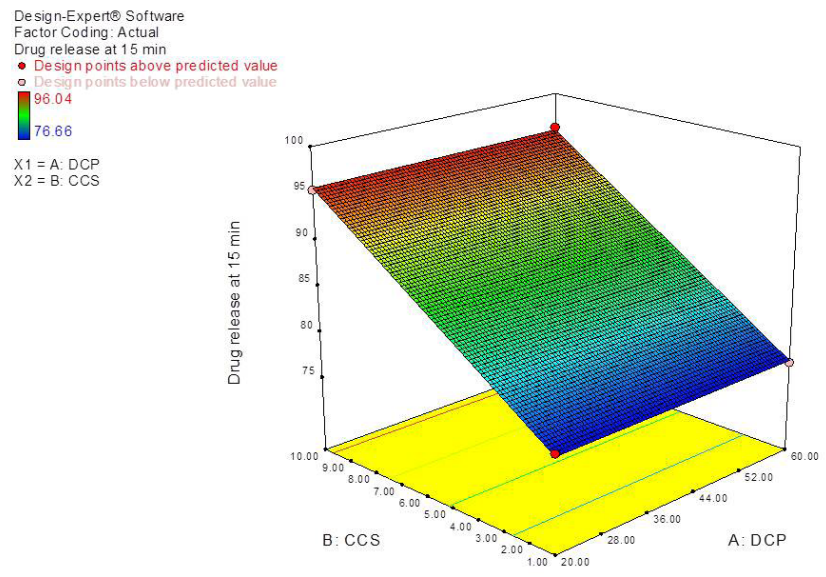

Figure 5: 3D response surface plots for in vitro drug release at $15 \mathrm{~min}$.

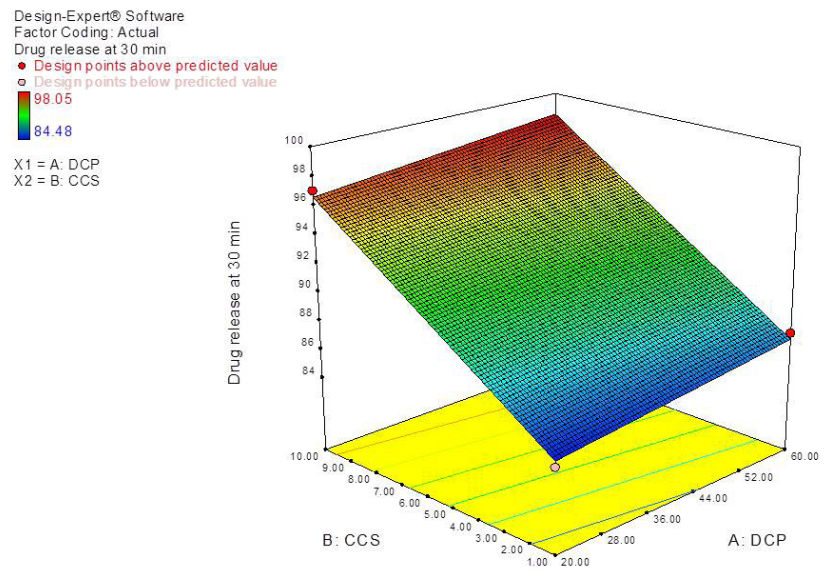

Figure 6: 3D response surface plots for in vitro drug release at $30 \mathrm{~min}$.

\section{DISCUSSION}

ODTs were formulated by application of response surface methodology of sitagliptin phosphate and understand the variables employed in the study had a great effect on the quality of formulation.

Experimental data for each response variable were fitted to the quadratic model and regression equation were generated to predict the responses. ${ }^{7}$
ODTs were prepared by direct compression method using DCP, as diluent and CCS as super disintegrant using design expert software 9.0 version, dissolution time at 5(Y1), 15(Y2) and 30(Y3) min was taken as response. Mathematical models in the form of regression equations and graphs were developed..$^{7-10}$ FTIR compatibility studies of drug with excipients were carried out prior to tablet preparation and it reveals that there was no physico-chemical interaction between drug and excipients. All the characteristic peaks of drug were present in the spectra of formulation, thus indicating compatibility between drug and excipients. The FTIR spectra of pure drug and formulation are shown in Figure 1. Four formulations were formulated by using $2^{2}$ level factorial design (Table 1,2) using design expert software version 9 and evaluated for precompression parameters like angle of repose, bulk density, tapped density, Carr's index and results shown in Table 3. All the parameters were carried out to study the powder flow characteristics in order to achieve tablets of uniform weight and were found to be well within the permissible limits.

The tablets were subjected to post compression evaluation parameters weight variation, thickness, hardness, friability, in vitro disintegration time verses wetting time and in vitro drug release (Table 4) (Figure 2,3 ) and all the formulations the results were found to be well within the permissible limits. The tablets had good mechanical strength with sufficient hardness and low friability. The drug content was also within pharmacopoeial limit (90-110\%). The wetting time was optimally low. The disintegration time of the DF3 formulation was high when compared to other formulations as shown in Figure 2.

Drug dissolution studies were performed for all four formulations. The DF1 formulation has shown minimum disintegration time $15.33 \mathrm{~s}$ and a maximum drug release $96.04 \%$ at $15 \mathrm{~min}$ as shown in Figure 3.

Statistical Optimization of formulations was validated by using ANOVA. Adequacy of the models at a confidence level of $90 \%$ is summarized in Table 5. The coefficient of determination $\left(R^{2}\right)$, indicates the proportion of total variability of the model explained and suggested that good fit model. ${ }^{12,13} R^{2}$ value should be as close to as 1 or at least $0.8 .{ }^{21}$ Hence the $R^{2}$ reflected to be goof fit between the predicted and the observed response values and can be used to assess model adequacy. ANOVA variance statistics is shown in Table 5 . The suggested sequential model sum of squares, lack of fit test (Showing Degrees of freedom, mean square, $f$ Value, $p$ value), model summary statistics is given in table 6 . The model was found to be statistically significant for responses Y1 and Y2 since $p<0.05$ and for response Y3 with $p>0.05$ the model is nonsignificant. Hence, dissolution at $5 \mathrm{~min}$. As shown in equation below, a statistical model incorporating interactive and polynomial terms was used to evaluate the responses. $\mathrm{Y}=\mathrm{b} 0+\mathrm{b} 1 \mathrm{~A}+\mathrm{b} 2 \mathrm{~B}$, Where $\mathrm{Y}$ is measured response associated with each factor level combination; b0 is an intercept representing arithmetic average of all quantitative outcomes of four runs; b1and b2 are regression coefficient computed from the observed experimental values of $\mathrm{Y}$. A and B are the coded levels of independent variables. ${ }^{13}$

The polynomial equation was used to draw conclusions after considering the magnitude of coefficients and the mathematical sign it carries, i.e. positive or negative. A positive sign signifies a synergistic effect, whereas a negative sign stands for an antagonistic effect. ${ }^{12,13}$ Regression equations for each response are as follows, $\mathrm{Y} 1=+72.57278-0.014875^{\star} \mathrm{A}+$ $1.81722^{\star} \mathrm{B}, \mathrm{Y} 2=+74.71500+0.001875^{\star} \mathrm{A}+2.09500^{\star} \mathrm{B}, \mathrm{Y} 3=+82.67778$ $+0.046250^{\star} \mathrm{A}+1.30222^{\star} \mathrm{B}$ (Table 5). The results of ANOVA in the Table 6 for the dependent variables demonstrate that the model was significant for both the response variables Y1 (Dissolution at $5 \mathrm{~min}$ ) and Y2 (Dissolution at $15 \mathrm{~min}$ ) whereas response variable Y3 (Dissolution at $30 \mathrm{~min}$ ) was found to be non-significant. It was observed that the two independent variables viz. A (DCP concentration) and B (CCS 
concentration) had a negative effect on dissolution at $5 \mathrm{~min}$ and positive effect on dissolution at $15 \mathrm{~min}$ (Y2) and $30 \mathrm{~min}$ (Y3). The DF1 formulation has shown minimum disintegration time $15.33 \mathrm{~s}$ and a maximum drug release $96.04 \%$ at $15 \mathrm{~min}$.

\section{CONCLUSION}

DoE Concept in formulation could pave way for adaptation of Quality Based Design (QbD) in pharmaceutical industry. RSM was successfully applied to optimize diluents and disintegrant concentration of orally disintegrating tablet of sitagliptin, capable of fast disintegration within the buccal cavity within $16 \mathrm{~s}$. The variables employed in the study had a great effect on the quality of formulation. Modeling of experimental data allowed the generation of useful equations for prediction of responses and was according to acceptance criteria for dissolution of ODT's.

\section{ACKNOWLEDGEMENT}

The authors would like to thank Vergo Pharma Research Laboratories Pvt. Ltd., Verna, Goa for providing the drug and excipients. Authors are also thankful to Principal, KLEU's College of Pharmacy, Hubli for support to carry out the work. The authors report no declaration of interests.

\section{CONFLICT OF INTEREST}

The authors declare no conflicts of interest.

\section{REFERENCES}

1. Pawar $H$, Varkhade $C$, Jadhav $P$, Mehra K. Development and evaluation of orodispersible tablets using a natural polysaccharides isolated from Cassia tora seeds. Integrat Med Res. 2014;3(2):91-8.

2. Raghavendra RNG, Ketan T, Bala S. Formulation and Evaluation of fast dissolving tablet of metaprolol tartarate using natural super disintegrant. Int J Pharm Clin Res. 2010;2(1):40-5.

3. Abha, Kaur LP. Super disintegrants: An arising exemplar in orodispersible tablets. Int J Drug Res Tech. 2015;5(1):1-12.

4. Reddy LH, Ghosh B, Rajneesh. Fast dissolving drug delivery systems: A review of the literature. Ind J Pharm Sci. 2002;64(4):331-6.

5. Xu X, Khan MA, Burgess DJ. A Quality by Design (QbD) case study on liposomes containing hydrophilic API: Formulation, processing design and risk assessment. Int J Pharm. 2011;419(1-2):52-9.
6. Awotwe-Otoo D, Agarabia C, Wu GK, Casey E, Read E, Lute S, et al. Quality by design: Impact of formulation variables and their interactions on quality attributes of a lyophilized monoclonal antibody. Int J Pharm. 2012; 438(1-2):16775.

7. Huang J, Kaul G, Cai C, Chatlapalli R, Hernandez-Abad P, Ghosh K, et al. Quality by design case study: An integrated multivariate approach to drug product and process development. Int J Pharm. 2009;382(1-2):23-32.

8. Patel TB, Patel TR, Suhagia BN. Formulation development of donepezil hydrochloride oral disintegrating tablets using quality by design approach. Int J Pharm Sci Res. 2016;7(5): 2097-108.

9. Malipeddi VR, Dua K Awasthi R. Development and characterization of solid dispersion-microsphere controlled release system for poorly water-soluble drug. Drug Deliv Transl Res. 2016;6(5):540-50.

10. Gorajana A, Rajendran A, Yew LM, Dua K. Preparation and characterization of cefuroxime axetil solid dispersions using hydrophilic carriers. Int J Pharm Investig. 2015;5(3):171-8

11. Kolluru LP, Gala RP, Shastri PN, Ubale RV. Design of Experiments: A Valuable "Quality by Design" Tool in Formulation Development. Nanopart Vac Deliv Sys. 2015;3:61-91.

12. Madhuresh D, Mishra HN, Deora NS, Baik OD, Meda V. A response surface methodology (RSM) for optimizing the gluten free bread formulation containing hydrocolloid, modified starch and rice flour. presentation at the CSBE/SCGAB 2013 Annual Conference University of Saskatchewan, Saskatoon, Saskatchewan, Canada. 2013

13. Ainurofiq A, Choiri S. Development and optimization of a meloxicam/ $\beta$-cyclodextrin complex for orally disintegrating tablet using statistical analysis. Pharm Dev Tech. 2018;23(5):464-75.

14. Khar, Vyas RK, Ahmad SP, Jain FJ, Gaurav K. Theory and practice of Industrial Pharmacy. $4^{\text {th }}$ ed. New Delhi, India: CBS Publishers and Distributors. 2018.

15. Elkhodairy KA, Hassan MA, Afifi SA. Formulation and Optimization of orodispersible tablets of flutamide. Saudi Pharm J. 2014; 22(1):53-61.

16. Puttewar TY, Kshirsagar MD, Chandewar AV, Chikhale RV. Formulation and evaluation of orodispersible tablet of taste masked doxylamine succinate using ion exchange resin. J King Saud Univ. 2010;22(4):229-40.

17. Jain RK. Formulation and evaluation of orodispersible metformin tablets: $A$ comparative study on isabgula husk and crospovidone as superdisintegrants. Int J Applied Pharm. 2010;2(3):15-20.

18. Rani JL, Abbulu K. Formulation and evaluation of fast dissolving tablets of saxagliptin. Int J Biol Pharm Res. 2014;5(5):408-14.

19. Brniak W, Jachowicz R, Pelka P. The practical approach to the evaluation of methods used to determine the disintegration time of orally disintegrating tablets (ODTs). Saud Pharm J. 2015;23(4):437-43

20. Priyanka M, Dasankoppa FS, Sholapur HN, Swamy NGN, Sajjanar V. Design, characterization and evaluation of mucoadhesive nasal in situ gelling formulations of venlafaxine hydrochloride for brain targetting. Indian Drugs. 2016;53(1):25-31.

21. Xiangli F, Wei W, Chen Y, Jin W, Xu N. Optimization of preparation conditions for polydimethylsiloxane (PDMS)/ceramic composite pervaporation membranes using response surface methodology. J Memb Sci. 2008;311(1-2):23-33.

Article History: Submission Date : 01-04-2020; Revised Date : 02-05-2020; Acceptance Date : 09-06-2020.

Cite this article: Dasankoppa FS, Sholapur HN, Byahatti A, Abbas Z, Komal S, Subrata K. Application of Response Surface Optimization Methodology in Designing Ordispersible Tablets of Antdiabetic Drug. J Young Pharm. 2020;12(2):173-7. 